\title{
Segregación residencial y estigmatización territorial. Representaciones y prácticas de los habitantes de territorios segregados
}

Ana Elorza. Consejo Nacional de Investigaciones Científicas y Técnicas (Conicet), Universidad de Córdoba, Córdoba, Argentina.

RESUMEN | Los distintos actores urbanos y las prácticas sociales que tienen lugar en las ciudades, materializadas estas en diferentes formas de producción de hábitat, contribuyen a la configuración de las representaciones construidas en torno a los tipos de territorios existentes y a sus residentes. Entre tales representaciones, que operan como signos distintivos y de diferenciación social, se encuentran los estigmas territoriales. En este marco presentamos un análisis comparativo de dos territorios segregados, cuyos orígenes han sido diferenciales: un barrio de vivienda social producido por el Estado, inaugurado en 2004; y un asentamiento desarrollado a través de una toma de tierra organizada por un grupo de familias el ańo 2013. Identificamos los aspectos comunes y divergentes entre sus habitantes, en relación a cómo experimentan cotidianamente el territorio barrial y la ciudad, en tanto proceso que les posibilita aprehender la posición que ocupan en el espacio social y urbano.

PALABRAS CLAVE | desigualdad social, segregación, imaginarios urbanos.

ABSTRACT | The different urban actors and social practices that take place in cities, materialized in different forms of production of habitat, contribute to the configuration of the representations built regarding the types of existing territories and its residents. Among those representations are the territorial stigmas, which operate as distinctive signs and of social differentiation among social groups. Given this framework, we conduct a comparative analysis of two segregated territories, whose origins have been differential: (1) A neighborhood of social housing produced by the state, inaugurated in 2004, and (2) a settlement developed through a land grab organized by a group of families in 2013. We identify the common and divergent aspects in relation to how they experience the neighborhood and the city on a daily basis, as a process that enables them to grasp the position they occupy in the social and urban space.

KEYWORDS | social inequality, segregation, urban imaginary 


\section{Introducción}

Desde el inicio de las ciudades, las distintas formas de apropiación de bienes y servicios generan diferencias entre los distintos grupos sociales, con la consecuente segregación de algunos de ellos en el territorio urbano. Este proceso, sin embargo, no se reduce a una "desigual distribución espacial de bienes y servicios", ya que en su base "hay límites sociales, imaginarios y calificaciones sociales" (Carman, Neiva Viera \& Segura, 2013, p. 18). Los distintos actores urbanos y prácticas sociales, materializadas estas en diferentes formas de producción de hábitat, contribuyen a la configuración de las representaciones construidas en torno a los tipos de territorios existentes y a sus residentes. Se trata de imaginarios que operan como signos distintivos y de diferenciación entre los grupos sociales. Entre tales signos se encuentran los estigmas territoriales, que se constituyen como fuentes de desventajas e instrumentos de diferenciación y de sostenimiento de las desigualdades sociales (Wacquant, 2007).

En los últimos veinte años, en América Latina se han realizado numerosos estudios sobre la segregación socioterritorial en relación con el acceso al suelo urbano y vivienda por parte de los sectores populares (Mayorga, García \& Hernández, 2017; Programa de Naciones Unidas para el Desarrollo [PNUD], 2009; Ruiz Tagle, Labbé, Álvarez, Montes \& Aninat, 2016; Sabatini, 2006; Sabatini, Wormald \& Rasse, 2013; etcétera). En esa línea se identifica una periferización de la población de menos ingresos, en áreas con deficiente acceso a recursos urbanos (servicios, equipamientos, trabajo, etcétera) y que cargan simbólicamente calificaciones negativas. Dentro de este vasto campo de producción, podemos identificar dos ámbitos de estudio: por un lado, los nuevos territorios generados por las políticas públicas estatales de barrios de vivienda social; y por otro, las experiencias de autoproducción del hábitat desde la "lógica de la necesidad" (Abramo, 2007).

En relación con la primera línea de estudios, trabajos realizados en diferentes ciudades de la región (por ejemplo, Santiago de Chile, México, Buenos Aires, Bogotá, entre otras) identifican como tendencia la localización de proyectos de vivienda cada vez más distante de áreas de centralidad, lo cual trae aparejado profundos problemas para las familias residentes: aumento de las distancias respecto de los lugares de servicio, la desestructuración de las redes sociales primarias y secundarias, las valoraciones negativas respecto al barrio debido a la inadecuada localización en los límites de la gran ciudad y el acceso a los servicios públicos e institucionales, todo lo cual incide en su configuración como barrios estigmatizados (Marengo \& Elorza, 2016; Rodríguez Chumillas, 2006; Ruiz Tagle, Labbé, Álvarez, Montes \& Aninat, 2016; Sabatini, Wormald \& Rasse, 2013).

En cuanto a la segunda línea de trabajo, refiere a reconocer la autoproducción del hábitat como una de las particularidades constitutivas de la urbanización de nuestra región, valorizada en tanto estrategia de autoorganización en la construcción de vivienda y de infraestructuras colectivas (Santillán Cornejo, 2015). En esta perspectiva, tal modalidad trascendería la dotación física de equipamientos o servicios, para apuntar a la reivindicación del sentido de pertenencia a la ciudad. Conlleva, por otra parte, el reconocimiento de los barrios marginales (Carman, Neiva Vieva 
\& Segura 2013) como estrategia de disputa no solo de los territorios urbanos, sino también de las representaciones construidas en torno a las villas y asentamientos como lugares peligrosos, vinculados a prácticas marginales y delictivas.

A modo de articular las dos perspectivas, en este trabajo presentamos un análisis comparativo de dos territorios caracterizables como segregados, con orígenes diferentes: un barrio de vivienda social producido por el Estado y un asentamiento desarrollado a través de una toma de tierra organizada por un grupo de familias. Identificamos en ellos aspectos tanto comunes como divergentes en relación a cómo sus habitantes experimentan cotidianamente el territorio barrial y la ciudad (la carga simbólica del lugar donde residen, el acceso desigual al espacio urbano, etcétera), como proceso que les posibilita aprehender la posición que ellos mismos y los distintos grupos sociales ocupan en el espacio social y urbano (Segura, 2012). En este sentido, buscamos aportar a la comprensión sobre cómo la segregación también se construye en el ámbito de las representaciones sociales, los estigmas territoriales producidos y las prácticas de los sujetos.

El estudio realizado tiene un enfoque interpretativo; la metodología implementada ha sido de tipo cualitativa, definiéndose, como estrategia de abordaje, dos estudios de caso, acotados a partir de criterios teóricos: el barrio de vivienda social Ciudad de los Cuartetos y el asentamiento Nueva Esperanza. Ambos casos fueron elegidos por su localización en áreas periféricas de la ciudad, que podrían ser caracterizadas como sectores segregados, con una concentración de población en condiciones de pobreza estructural (Marengo \& Elorza, 2016). No obstante esta línea común, se trata de asentamientos planificados y producidos de manera diferente, lo cual arroja pistas para pensar en las representaciones y prácticas de sus residentes en torno a su hábitat. Realizamos entrevistas individuales a pobladores de estos territorios recuperando las distintas formas narrativas que hablan sobre un lugar, lo cual estaría evidenciando la manera en que el sujeto lo imagina y representa (De Alba, 2010) y desarrolla prácticas en relación con él.

\section{Segregación residencial, representaciones y estigmatización territorial}

Las ciudades son espacios atravesados por tensiones intrínsecas al proceso de urbanización y a su conformación, ya que surgen por concentraciones geográficas y sociales de un producto excedente socialmente definido. Las desigualdades, derivadas del modo de producción capitalista, se traducen en diferentes condiciones de acceso a lo urbano. La localización geográfica de los distintos grupos sociales se vincula con las modalidades diferenciadas en que estos grupos acceden a la ciudad y a los recursos urbanos, y ponen en evidencia procesos de desigualdad social que tienen su correlato en lo territorial (Di Virgilio \& Perelman, 2014). Sin embargo, la comprensión de la segregación no solo implica reconocer este proceso de desigual distribución espacial de bienes y servicios, sino también las construcciones de sentidos (representaciones, descalificaciones, estigmatizaciones, etcétera) que se constituyen como fundamentos de ellos. 
A modo analítico, recuperamos la clasificación de Carman, Neiva y Segura (2013, pp. 19-24) sobre las distintas modalidades de la segregación que se pueden identificar en las ciudades:

a. La segregación acallada, que alude a una producción directa, aunque implícita, de situaciones de confinamiento, de una segregación invisible; se presenta como una medida asistencial o una política de inclusión, cuyo efecto es la exclusión o el desplazamiento de sectores populares.

b. La segregación por default, que refiere a los efectos socioespaciales de un prolongado abandono estatal de los habitantes de una zona de relegación urbana; así, esta modalidad de segregación es producida indirectamente por una conjunción de políticas de olvido por parte del Estado.

c. La segregación presuntamente indolente o positiva, que se materializa en los procesos de autosegregación de la clase acomodada, tanto en las torres country del corazón de la ciudad capital, como en las urbanizaciones cerradas suburbanas.

d. Y la segregación agravada, que hace referencia a los procesos de refuerzo de situaciones de confinamiento socioespacial. En este caso, los grupos vulnerables interiorizan la hostilidad de ser segregados una y otra vez cuando se ven reforzadas situaciones de confinamiento socioespacial, o bien cuando existe un efecto acumulativo de experiencias que dificultan la integración de un grupo a la ciudad que habita.

Esta clasificación contribuye a la comprensión de los diferentes procesos que configuran la segregación residencial y los actores que participan en ella -en especial, el Estado en su rol en la omisión, definición y ejecución de políticas con anclaje territorial-; y en relación con esto, a la forma en que se va produciendo la posición que ocupan los distintos grupos en el espacio social y urbano. Siguiendo a Bourdieu (1999), podemos decir que el espacio social está inscrito en las estructuras espaciales a la vez que en las estructuras mentales, en los habitus de los agentes; por lo tanto, las grandes oposiciones sociales objetivadas en el espacio físico (para nuestro caso de estudio, las oposiciones barrio / villa, centro / periferia, etcétera) tienden a reproducirse en los espíritus y en el lenguaje, en la forma de oposiciones constitutivas de un principio de visión y división. Es decir, en tanto categorías de percepción y evaluación o de estructuras mentales. En otros términos, en las representaciones sociales y en las prácticas que desarrollan los agentes.

La experiencia de habitar en la ciudad es distinta según el tipo de hábitat en el que se reside y a partir del cual se establecen relaciones con el resto del territorio metropolitano, las mismas que cambian a partir de las diferencias culturales, sociales o étnicas entre los sujetos, y de su ubicación socioespacial. Estas variaciones "reflejan el poder desigual de los actores en su relación con el espacio, y en particular en su capacidad para domesticarlo, es decir, para convertirlo en algo que tiene significado y uso para cada quien" (Duhau \& Giglia, 2008, p. 21). Así, los distintos territorios (barrios, countries, villas, asentamientos, barrios de vivienda social, etcétera), con características y calidades diferentes, contribuyen a la configuración de 
las representaciones construidas en torno a los distintos tipos de hábitat y a sus residentes, como signos distintivos y de diferenciación entre los grupos sociales.

Ahora bien, avancemos en la reflexión en torno a los procesos de desigualdad expresados en la ciudad, en que la segregación residencial es una de sus manifestaciones, y que tiene como base la interacción social entre sujetos. Para Goffman (1998), la sociedad establece los medios para categorizar a las personas y definir el complemento de atributos que se perciben como corrientes y naturales en los miembros de cada una de esas categorías. Cuando uno de los atributos asignados a los sujetos es desacreditador, valorado negativamente, se puede considerar como un estigma. En este sentido, se entiende por estigma un estereotipo definido a partir de la percepción de cualidades negativas ${ }^{1}$ respecto de una persona o grupo social. Tales cualidades asignadas de carácter descalificatorio, que establecen marcas o huellas indelebles y permanentes en el tiempo en las personas, tienen implicancias prácticas de diferenciación y segregación. "Así a la persona que tiene ese atributo, dejamos de verla como una persona total y corriente para reducirla a un ser menospreciado [...] practicamos diversos tipos de discriminación, mediante la cual reducimos en la práctica, aunque a menudo sin pensarlo, sus posibilidades de vida" (Goffman, 1998, pp. 12-15).

Vinculando este concepto con el territorio, Wacquant (2007) refiere a la identificación del espacio como un anclaje distintivo de deslegitimación social. El espacio se instituye también como representación de la alteridad a través del estigma ("estigma territorial"), como "otro" extrańo, lejano e inaprehensible. Este autor mencionado hace mención del poderoso estigma asociado a la residencia en los espacios restringidos y segregados, que denomina "barrios del exilio", en que quedan cada vez más relegadas las poblaciones marginadas o condenadas a la superfluidad por la reorganización posfordista de la economía y el Estado. El barrio estigmatizado degrada simbólicamente a quienes lo habitan, los cuales hacen lo mismo con él; la estigmatización territorial refuerza el "encadenamiento a un lugar" de los sectores con menos capitales, los amarra a las peores áreas de la ciudad (Bourdieu, 1999). De esta manera, las representaciones se constituyen en una fuerza activa de segregación que ejerce una exclusión material y simbólica de los habitantes de los barrios con "mal" prestigio, y representan barreras reales en las posibilidades de acceso a servicios, bienes y recursos, lo cual significa procesos de deterioro de las condiciones de vida para su población (Kessler, 2012; Wacquant, 2007).

Es importante conocer la experiencia subjetiva de los residentes que son asignados a las zonas etiquetadas como peligrosas, porque ese estigma territorial contribuye a explicar las distintas prácticas. Como plantean Wacquant, Slater y Borges Pereira (2014), las estrategias sociosimbólicas desarrolladas

Para hacer frente a la denigración espacial cubren un amplio abanico que va desde la sumisión hasta la resistencia y su adopción depende de la posición y trayectoria dentro del espacio físico y social. La estigmatización territorial no es una condición

1 Goffman (1998) realiza una clasificación de los estigmas según su naturaleza: estigmas corporales, estigmas del carácter y estigmas tribales. 
estática o un proceso neutral, sino una forma significativa y perjudicial de acción mediante la representación colectiva centrada en un lugar determinado. (p. 220)

En Argentina, se reconoce un fuerte estigma hacia los habitantes de las villas: "la identidad del sector estuvo siempre en tensión entre el ser trabajador y el ser villero; existe cierto fabulario colectivo según el cual los villeros son sucios, feos y malos, además de delincuentes, vagos e ignorantes" (Merklen, 1997). Esto representa barreras para el acceso a los servicios y recursos necesarios para la reproducción cotidiana; y, como estrategia, lleva a los residentes de estos territorios a ocultar el domicilio y, en muchos casos, a construir una identidad que marca la diferencia con los otros villeros (Elorza, 2009; Merklen, 1997).

\section{Los casos de estudio: un barrio de vivienda social y un asentamiento}

La ciudad de Córdoba (Argentina) ${ }^{2}$ se ha caracterizado desde sus inicios por la desigual apropiación del espacio según la condición socioeconómica de los grupos sociales. Desde la década de los cuarenta y debido a los procesos migratorios del campo a la ciudad en el marco de la política económica de industrialización del país, comienzan a configurarse villas como estrategia de producción de hábitat por parte de familias sin posibilidades de acceder vía el mercado formal de tierra y vivienda. Las villas, producidas a través de ocupaciones individuales (familiares) de tierras fiscales o privadas, se localizaban en áreas centrales e intermedias de la ciudad, dado que ofrecían mayores oportunidades para el desarrollo de actividades (laborales, educativas, culturales, etcétera) y de acceso a servicios y equipamientos sociales. En el contexto de su surgimiento, el término "emergencia" aplicado a estos asentamientos hacía referencia a una residencia transitoria para las familias pobres, hasta que pudieran acceder a un trabajo con salario justo y a una vivienda adecuada (Zilocchi, 2007). Recién en los años setenta, frente a presiones y demandas desde organizaciones vecinales y villeras, se comenzó a desarrollar acciones tendientes a mejorar la infraestructura y servicios de los barrios y villas (Elorza, 2016).

A partir de 1991, con la incidencia del neoliberalismo ${ }^{3}$ en las definiciones políticas del país, que implicó un achicamiento del gasto social y redefinición del rol del Estado en el abordaje de la cuestión social, las políticas de vivienda se orientaron a la descentralización de los recursos, la diversificación de los programas, la creciente preocupación por mejorar la eficiencia y la eficacia de las acciones, y promovieron la incorporación de actores sociales. En este marco, se gestó la Mesa de Concertación de Políticas Sociales, un espacio multiactoral integrado por el

2 La ciudad de Córdoba (capital de la provincia de Córdoba) es reconocida como la segunda ciudad con mayor cantidad de habitantes de Argentina, después de la Ciudad Autónoma de Buenos Aires registra, según el Censo Nacional de 2010, 1.315.423 personas.

3 Estos cambios estuvieron regidos por los principios del Consenso de Washington, delimitados por los organismos internacionales de financiamiento. 
Ministerio de Desarrollo Social, la Municipalidad de Córdoba, distintas $\mathrm{ONG}^{4} \mathrm{y}$ la Unión de Organizaciones de Base por los Derechos Sociales (uOBds), que se desarrolló durante el periodo 1992 a 1998. Su objetivo era discutir las políticas y herramientas encaminadas a mejorar la calidad de vida, como alternativa a las prácticas tradicionales. La mayoría de los proyectos estuvieron centrados en el hábitat, incluyendo el acceso a la tierra, la construcción del equipamiento comunitario, la provisión de infraestructura básica (Marengo \& Elorza, 2009). En el periodo 20032010, el gobierno de la provincia de Córdoba ejecutó una política habitacional cuyo objetivo era erradicar las villas ${ }^{5}$ en riesgo ambiental. El resultado de esta política ha sido la erradicación de 70 villas a 39 nuevos barrios, en su mayoría localizados en áreas periféricas de la ciudad. Los nuevos conjuntos habitacionales responden a una misma tipología organizativa del territorio, con un "arco de entrada" al barrio, manzanas con viviendas uniformes $\left(\mathrm{de} 42 \mathrm{~m}^{2}\right.$ ) y equipamiento social (escuelas, centro de salud, posta policial), idénticos para todos los casos, y fueron denominados como "barrios-ciudades" (ejemplo, Ciudad de Mis Sueños, Ciudad Sol Naciente, Ciudad Evita, etcétera).

En paralelo, se produjo un incremento de las situaciones de informalidad urbana, en especial las tomas de tierra, ${ }^{6}$ debido al sostenido aumento del valor de los terrenos en la ciudad, la escasez de tierra urbanizada al alcance de las familias de bajos ingresos y las políticas públicas habitacionales focalizadas. Cabe destacar que, a través de esta estrategia en el acceso al hábitat, se produjeron asentamientos con rasgos diferenciales a las antiguas villas, lo cual da cuenta de la percepción de los pobladores respecto del asentamiento no como una solución habitacional transitoria, sino como una mejora a corto y mediano plazo en el acceso a la tierra. Como plantean Varela y Cravino (2008), estos territorios presentan, a modo general, ciertas características: sus trazados urbanos tienden a ser regulares y planificados, semejantes el amanzanamiento habitual de los loteos comercializados en el mercado de tierras; son organizados colectivamente con una estrategia previa; están ubicados, en su mayoría, sobre tierra privada que fuera vacante; luego de la invasión del terreno se busca su legitimación, reivindicando la oportunidad de pagarlo a fin de obtener la propiedad sobre él; las viviendas allí construidas, debido a que la ocupación de la tierra implica vivir en el lugar, evolucionan en el tiempo, con mejoras de distinto tipo; sus pobladores, en todos los casos, son actores sociales previamente "urbanizados", entre otras.

En resumen, en este periodo 2000-2015, el acceso al hábitat por parte de los sectores populares en la ciudad de Córdoba estuvo marcado por la política

4 Las organizaciones de base contaban con el apoyo, asesoramiento técnico y capacitación de cuatro organizaciones no gubernamentales: Servicio Habitacional y de Acción Social (Sehas), Centro de Comunicación Popular y Asesoramiento Legal (Cecopal), Servicio en Promoción Humana (Serviproh) y la Mutual Carlos Mujica.

5 Hacemos referencia a asentamientos informales que se comenzaron a producir en Argentina a partir de la década de 1940 debido a los procesos migratorios del campo a la ciudad en el marco de la política económica de industrialización por la sustitución de importaciones; término análogo a 'favelas' en Brasil, 'campamentos' en Chile o 'colonias' en México.

6 Según un relevamiento realizado el año 2015, se identifican 23 "tomas de tierra" en la ciudad (Monayar, 2015). 
habitacional focalizada y las acciones colectivas de autoproducción del hábitat, y en la mayoría de los casos los nuevos territorios se encuentran en la periferia de la ciudad. Cabe destacar que las condiciones de vida en las zonas periféricas están lejos de ser homogéneas, por lo que se hace referencia a "periferias" (Caldeira, 2010); en los casos que analizamos, se trata de los sectores de la ciudad donde el valor de los terrenos es más bajo y con menor calidad urbana.

Cravino (2013) plantea que el estudio de la experiencia y las prácticas urbanas, las representaciones e imaginarios, las formas de uso y consumo del espacio urbano, dan cuenta de que este espacio es producto y deviene tanto de una realidad material, como de los diferentes modos en los cuales esta realidad es experimentada y vivida por los sujetos. En este sentido, nos interesa conocer las representaciones y prácticas territoriales que construyen los sujetos habitantes de dos contextos socioespaciales producidos a través de dos lógicas distintas: la del Estado, a través de políticas de vivienda social; y la lógica de la necesidad, desarrollada por un grupo de familias como procesos de autoproducción del hábitat. Como mencionamos anteriormente, los casos de estudio han sido seleccionados dada su localización en áreas periféricas, las cual también podríamos caracterizar como segregadas: barrio Ciudad de los Cuartetos y el asentamiento Nueva Esperanza (figura 1).

Figura I | Ciudad de Córdoba.

Localización de Ciudad de los Cuartetos y Nueva Esperanza

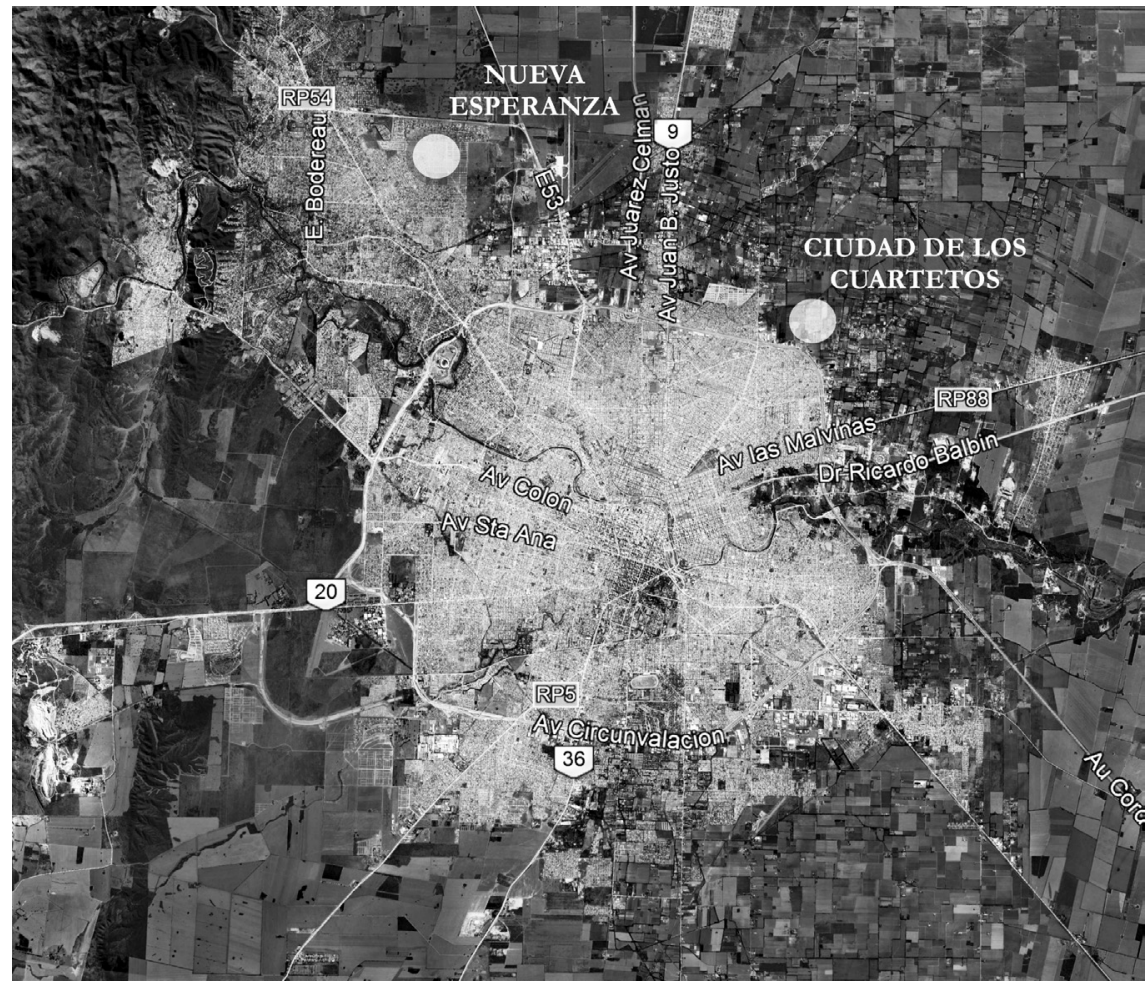

FUENTE ELABORACIÓN PROPIA CON BASE EN GOOGLE EARTH 
El barrio Ciudad de los Cuartetos es uno de los nuevos territorios construidos por esta política pública de vivienda social. Se encuentra localizado en la zona noreste de la ciudad, en un sector en el que las urbanizaciones residenciales están desarticuladas dentro de un contexto rural-industrial.

Este barrio fue inaugurado en noviembre del año 2004 y está conformado por 418 viviendas y el equipamiento comunitario (escuelas, centro de salud, comisaria, comedor de ancianos, centro de cuidado infantil y espacios verdes). Respondiendo a la tipología única planificada desde el programa, la entrada al barrio está demarcada por un arco en el que se expone su nombre. Su territorio se encuentra dividido en dos sectores por medio de un amplio espacio verde, sin equipamiento ni mantenimiento. Esta separación física se vincula a dos momentos de la construcción y adjudicación de las viviendas, pero también a la identidad colectiva de sus habitantes. En un primer momento, el 29 de mayo de 2004, fueron relocalizadas las familias provenientes de los asentamientos Villa El Chateau, Villa Urquiza y La Salada, por lo cual los vecinos decidieron nombrar al barrio como 29 de Mayo. ${ }^{7}$ Unos meses más tarde se construyó el sector posterior, destinado a las familias de Parque Liceo

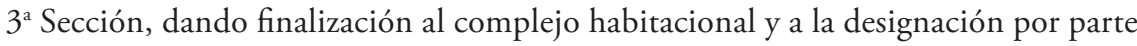
del gobierno como Ciudad de la Canción (figura 2).

Figura 2 Foto área de Ciudad de los Cuartetos y características del barrio
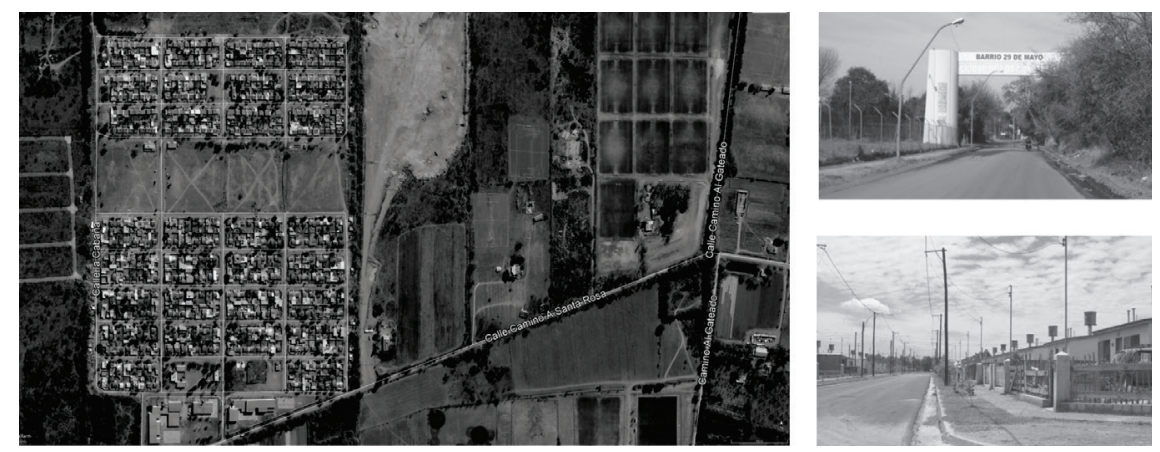

FUENTE ELABORACIÓN PROPIA CON BASE EN GOOGLE EARTH

El otro caso de estudio es el asentamiento Nueva Esperanza, situado en el sector noroeste de la ciudad de Córdoba, al borde del ejido municipal. En los últimos veinte años este sector ha sufrido importantes transformaciones, vinculadas al proceso de extensión y conurbación con el municipio de Villa Allende. Ha habido un importante incremento de población, debido a la ejecución de barrios de vivienda social y la producción de barrios cerrados a través de emprendimientos inmobiliarios.

$7 \quad$ Esta fecha es significativa para la ciudad y el país, ya que el 29 de mayo de 1969 se desarrolló una jornada de resistencia encabezada por el movimiento obrero y estudiantil contra la dictadura militar gobernante a nivel nacional, que fue reconocida como "el Cordobazo". La pueblada debilitó al gobierno militar y fue uno de los factores que llevó a la renuncia de Juan Carlos Onganía al año siguiente, lo que dio paso a una salida electoral que terminó concretándose con las elecciones de 1973. 
El origen de este asentamiento tuvo lugar el año 2013, con la toma de un terreno cercano por aproximadamente cien familias provenientes de diferentes barrios de la ciudad. En ese momento, la mayoría de esas familias se encontraba alquilando viviendas o residía con otros hogares, por lo que participar de la toma de tierra les significaba la posibilidad de obtener un lote propio para construirse una solución habitacional.

Cabe destacar que ese proceso de asentamiento estuvo atravesado por fuertes disputas entre actores por el control del territorio. El terreno, de propiedad de la Dirección de Vivienda de la Provincia de Córdoba, estaba destinado a proyectos vinculados a una política de suelo urbano dirigida a población de ingresos medios. Asimismo, colinda con el country San Isidro, un predio de la empresa inmobiliaria Mediterránea, en el que se proyecta realizar un barrio cerrado y barrio Policial Anexo. Las familias tuvieron que resistir acciones represivas por parte del poder policial y Judicial y de amedrentamiento de las empresas inmobiliarias con intereses en ese sector de la ciudad. Desde ese momento a la actualidad, se ha consolidado el asentamiento en cuanto a las condiciones materiales necesarias para la reproducción cotidiana de las familias (autoconstrucción de las viviendas y de la infraestructura) que contribuyen a la apropiación del territorio, como la organización social orientada a colectivizar las demandas y las estrategias en las luchas por las reivindicaciones de los derechos a la ciudad (figura 3).

\section{FIgURA 3 | Foto área de Nueva Esperanza y características del asentamiento}
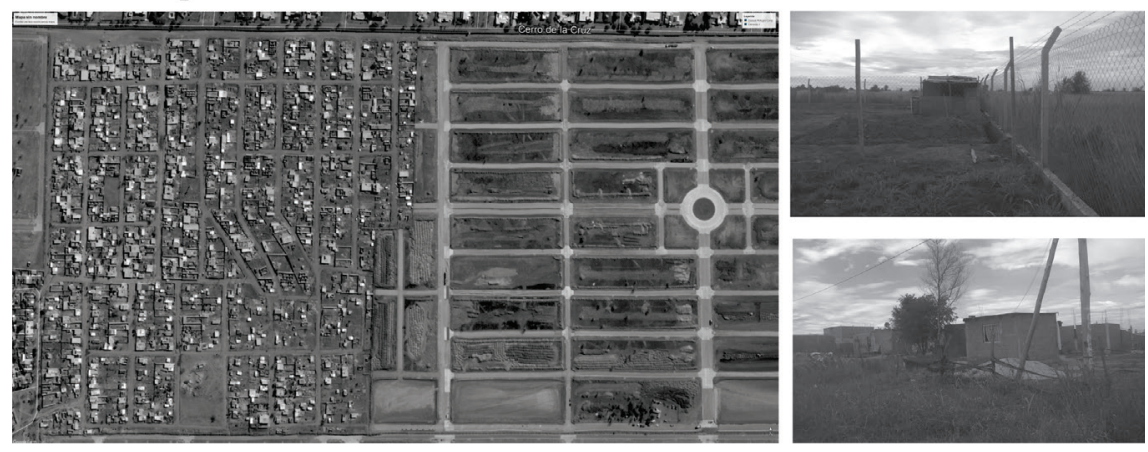

FUENTE ELABORACIÓN PROPIA CON BASE EN GOOGLE EARTH

A continuación, recuperamos a través de entrevistas individuales realizadas a referentes y vecinos y vecinas de los dos territorios analizados, los relatos que dan cuenta de las representaciones, estigmatizaciones y prácticas que construyen los sujetos habitantes de estos contextos socioespaciales, y que permiten identificar aspectos comunes y divergentes en relación a cómo experimentan cotidianamente el territorio barrial y la ciudad. 


\section{Fronteras materiales y simbólicas que marcan desigualdades}

Distintos trabajos dan cuenta de una correspondencia entre la localización residencial de la población, y la capacidad de acceder a recursos de calidad que pudiesen garantizar estándares de bienestar social. Señalan en general que, en la periferia de la ciudad, en los sectores donde reside mayoritariamente la población de bajos ingresos, esta estructura de oportunidades es notablemente inferior a la de los sectores centrales (Sabatini, 2006; Di Virgilio \& Perelman, 2014).

En Ciudad de los Cuartetos, por su localización en la periferia, el barrio es percibido por sus residentes como un espacio aislado. Esto, sumado a las características de s entorno rural-industrial, lleva a que sea entendido como un espacio sin oportunidades, en especial para los jóvenes. Como expresa una de las vecinas, "el otro día un chico me decía que no había nada acá; miraba para allá, todo campo; miraba para allá [mientras seńala el otro lado], 'todo campo', me decía llorando. No, acá no hay nada, nada para hacer..." (Marta, 57 años).

Los vecinos perciben claramente la desigual provisión, calidad y acceso a oportunidades en distintas áreas de la ciudad, cuestiones centrales en las prácticas tendientes a la reproducción social cotidiana de las familias. Sin embargo, la noción de 'aislamiento' no solo está vinculada a la localización periférica del barrio, sino que se ve reforzada por su denominación de "barrio-ciudad" y su arquitectura, el cual irrumpe en una trama discontinua y sin barrios vecinos.

En los relatos obtenidos durante las entrevistas, aparece la representación de la división entre el barrio y la ciudad, caracterizados en términos opuestos: adentro y afuera (Segura, 2006). Como expresa una vecina, "cualquier circunstancia te obliga a salir del barrio a buscar algún tipo de cosa, que es lo que no hay en el barrio; para la escuela hay que ir afuera, para la salud hay que ir afuera..." (Susana, 40 años). Lo mismo en palabras de un adolescente varón: "mejor hubiera sido que nos dejaran en el Liceo [por una de las villas de la cual provienen], porque estamos tirados acá adentro, no tenés salida para ningún lado...”.

Esta oposición entre adentro y afuera denota la percepción de las múltiples fronteras que configuran el territorio: geográfica (estar en la periferia), materialarquitectónica (el arco de ingreso al barrio), simbólica (la denominación de barriociudad) y social.

En Nueva Esperanza, si bien es un territorio autoproducido por los vecinos, las fronteras materiales fueron construidas por los actores propietarios de los terrenos colindantes. En este caso podemos evidenciar que cuando la distancia espacial 'prudente' entre las clases sociales cesa de estar garantizada, se suelen construir barreras físicas que aíslen lo que, desde las percepciones dominantes, está demasiado próximo (Carman, Neiva \& Segura, 2013). Este asentamiento ha sido delimitado a través de cercos perimetrales que lo mantienen separado del country y de los terrenos de la empresa inmobiliaria, y del perteneciente a la Dirección de Vivienda. Si bien estos dos terrenos se encuentran vacíos aún, la estrategia del cercado se vincula al control de la expansión del asentamiento y "de un paisaje de pobres", como lo define Carmen (45 años), lo cual representaría una desvalorización del suelo. 
Debido a las materialidades señaladas que circundan el asentamiento, la única vía de acceso a él es una calle que conecta al barrio Policial Anexo, que es significada por los vecinos como una conexión entre el adentro y afuera. A diferencia del barrio de vivienda social analizado, el adentro del asentamiento es sentido como un espacio de protección y seguridad frente al afuera lleno de peligros, como lo expresan algunas mujeres entrevistadas: "saliendo del barrio, de acá para allá pasan muchas cosas..." (Luciana, 36 años); “...cuando salís a comprar y te bajas del colectivo, llegas a tu casa y capaz que volvés sin las cosas, porque te las robaron allá afuera” (Karen, 27 ańos). Esta idea de un adentro protegido se vincula a las relaciones de proximidad y de reconocimiento entre todos los vecinos que colectivamente construyeron el barrio y la lucha frente a los procesos represivos de desalojo: "somos familia [ríe], somos como hermanos" (Irene, 32 ańos).

Estas fronteras materiales, sociales y simbólicas modelan la vida social de estas familias, que se estructura y depende, en gran medida, de la movilización de (escasos) recursos y la elaboración de variadas estrategias para atravesar la frontera con la finalidad de acceder a bienes y servicios escasos o ausentes en el barrio (trabajo, salud, educación, recreación), necesarios para la reproducción de las condiciones de vida (Segura, 2006).

\section{La estigmatización territorial sobre estos barrios y sus pobladores}

Para Wacquant (2007), los estigmas territoriales no son solo fuente de desventajas, sino, al mismo tiempo, instrumentos de diferenciación social y, sobre todo, expresión de una violencia simbólica que reproduce y consolida las relaciones de poder y las desigualdades de la estructura social.

En Ciudad de los Cuartetos, el aislamiento del barrio respecto del resto de la ciudad no solo es entendido por los entrevistados como una separación física, geográfica, sino también simbólica, atribuida al nombre del barrio. Marta (57 años), una militante con larga trayectoria en la villa Chateau y ahora en el barrio, nos comenta el conflicto surgido por su denominación. Como resultado de un proceso participativo que desarrollaron los vecinos para elegir un nombre que representara al barrio y, por lo tanto, a ellos, fue elegido " 29 de Mayo", en honor a la fecha en que les fueron adjudicadas las viviendas. Sin embargo, en la inauguración oficial del barrio se dio a conocer el nombre definido por los funcionarios públicos: "Ciudad de los Cuartetos”. Esto generó descontento y reclamos por parte de los vecinos:

Un día veíamos que levantaban un cartel, ahí atrás de la escuela y ahí vimos "Ciudad de la Canción”. Nos pusimos relocos, porque habíamos elegido el nombre y vino hasta el gobernador a inaugurar y le dijimos que era muy arbitrario, al nombre ya lo elegimos nosotros... Y bueno, tanto quilombo que le hicimos que tuvieron que agregarle al cartel "29 de Mayo". Pero fue horrible [...] más allá que nos gusta la música, es como que te discriminan, entendés. Más que se llama "ciudad". Ellos nos quieren lejos, quieren que hagamos todo acá. (Marta, 57 años)

A partir de esta expresión, se evidencian dos aspectos importantes: por un lado, un claro reconocimiento por parte de la vecina de la decisión política de sostener la 
diferenciación social en el territorio, trasladando a la población villera a la periferia y produciendo los nuevos territorios de los barrios-ciudades, con una arquitectura distintiva que contribuye a mantener también las diferencias sociales y simbólicas; y por el otro, las estrategias colectivas de resistencia por parte de los pobladores ante la imposición de la denominación del barrio, a través de las cuales consiguieron negociar con las autoridades un nombre doble "29 de Mayo-Ciudad de los Cuartetos". Esta doble denominación representa para ellos la posibilidad de desarrollar ciertas prácticas de ocultamiento de su lugar de residencia, como nos explica Jéssica (25 años): "yo digo que soy de 29 de Mayo, que nadie lo conoce...”.

La política de vivienda ha desempeñado un papel central en la construcción de las representaciones sociales en torno a la figura del "habitante de un barrio-ciudad", lo cual da cuenta de que el proceso de estigmatización territorial no es una condición estática (Wacquant, Slater \& Borges Pereira, 2014). A partir de las relocalizaciones de las villas y la configuración de los nuevos territorios de los barrios-ciudades, también se van reconfigurando los estigmas construidos en torno al estereotipo de los villeros, que si bien ahora ya residen en un barrio, siguen siendo discriminados, como señalan los entrevistados:

JÉssica: Cuando decís "Ciudad de los Cuartetos" te miran con una cara... Pero bueno, yo digo 29 de Mayo, que nadie lo conoce. En cambio vos decís Ciudad de los Cuartetos, Ciudad Angelelli, Ciudad de Mis Sueños, y es como que te marcan un poco...

ENTREVISTADORA: ¿Por qué crees que se produce eso?

JÉssICA: Y, porque dicen que los barrios-ciudades vienen de la villa, y entonces ahí te ponen, te marcan...

De esta manera, en los casos en que es posible ocultar la pertenencia territorial, buscan sortear el estigma que opera negativamente para la obtención de ciertos recursos, por ejemplo el empleo, como lo plantean Gustavo (26 años): "si sos de acá ya creen que vas a robar [ríe]"; y también Gisela (30 años): "si vos decís 'Ciudad de los Cuartetos', como que te miran 'de a dónde viene esta' [...]. A mi marido le pasó cuando quiso entrar a trabajar en un country, no lo tomaron...”.

Más allá de las diferencias territoriales entre los dos casos, en Nueva Esperanza las representaciones construidas en torno a la visión de los "otros" no difiere significativamente de lo mencionado anteriormente. Así lo expresan los vecinos:

Nosotros para ellos somos unos usurpadores, unos negros de mierda, los choros. (Paola, 34 años)

Hay muchos que no toleran la villa, como nos dicen, un asentamiento, que son todos villeros; pero nos pueden decir eso porque vivimos en un asentamiento, pero somos todos gente de trabajo [...]. Te discriminan mucho por vivir en un asentamiento, y eso pasó y va a pasar siempre, siempre hubo [pero], somos gente trabajadora... (Carmen, 45 años)

Para ellos nosotros somos unos microbios que nos quieren sacar a toda costa; pero nosotros no nos vamos a ir... (Karen, 27 años) 
Cabe destacar que estas calificaciones negativas trascienden lo subjetivo, pues también tienen su correlato en el acceso a servicios (de transporte, o de emergencias), que son inminentemente territoriales y a los cuales no pueden acceder por vivir en un barrio etiquetado como "zona peligrosa" o "zona prohibida". En ambos casos, las entrevistadas mencionan que las ambulancias y taxis no "entran" al barrio: "lo que pasa, uno, que no tenés un vehículo para salir; se te enferma un chico a la madrugada o tenés que salir por una urgencia, no podés salir de acá; los 'remises' no quieren entrar, y depende que algún vecino te quiere hacer un favor" (Gisela, 31 años). En estas circunstancias, en ocasiones se delega la responsabilidad a uno de los dirigentes barriales: "él nos lleva [ríe]. Lo llaman y ahí el Armando corre al hospital, es nuestra ambulancia..." (Rosa, 41 años).

En estos relatos podemos identificar el reconocimiento por parte de los vecinos de la carga simbólica de sus barrios y de ser portadores de estigmas territoriales que, en palabras de Saraví (2008), hacen presente, remarcan, establecen y afirman que no somos todos iguales. Es significativo que estos estigmas territoriales creen la ilusión de estar escindidos de la estructura social, y con ello planteen una desigualdad naturalizada. En el trabajo de campo realizado nos encontramos con una clara apreciación de esta desigualdad por parte de los sujetos depositarios de dichos estigmas. Si bien no identifican las causas estructurales de esta diferenciación, los entrevistados son conscientes de ser estigmatizados, debido a la evidente relación entre las representaciones sociales construidas en torno a ellos (los pobres, los villeros, etcétera) y las prácticas que desarrollan los "otros", los que "viven mejor que ellos", al decir de Marcos.

\section{La construcción de sentidos en torno a lo barrial}

El proceso de habitar de los territorios barriales implica acciones y prácticas vinculadas a la reproducción cotidiana de las familias y, a su vez, a la construcción de sentidos y representaciones del espacio residencial (Mele, 2016). Sobre estos sentidos encontramos las mayores diferencias entre los relatos de los entrevistados de los dos casos analizados.

En Ciudad de los Cuartetos, la valoración del barrio se encuentra atravesada por el acceso a una vivienda y barrio nuevo, ya que las familias provenían de las villas. En este sentido, los vecinos entrevistados dan cuenta de este cambio:

Acá tenemos agua; en la villa, no. Allá teníamos que acarrear agua, o esperar que venga el camión. Acá tenemos luz [...] Yo, donde vivía en la villa, no era una así como esta casa; era una piecita chiquita... En cambio acá, una que ya es mi casa, los chicos tienen sus piezas, todo... (María, 55 años)

Me gusta, me gusta el barrio, porque tenés bien instalada la casa; es cómoda, es cómoda; tengo todo lo que una persona anhela. Tenés todo bien instalado, tenés agua... En comparación a la villa, estamos diez mil veces mejor, hablando de la casa $[\ldots]$ que es algo, es algo impagable. Hay algunos que no lo valoran, pero, si yo hubiera tenido que comprar una casa hecha, no sé, no me hubiera alcanzado la vida... (Graciana, 46 años). 
En estas expresiones podemos identificar una alta estima hacia la "casa propia", que deriva de su potencial para compensar las exclusiones sociales vividas, así como por otorgar seguridad a su propietario, relacionada también con la "idea de progreso", todo lo cual se va conformando en una comparación constante con la antigua casa de la villa. Cabe destacar que la valoración de la "casa" que realizan los vecinos, que -como hemos dicho- es positiva, se encuentra fragmentada respecto del territorio barrial; es decir, se valora la casa propia pero no el entorno, debido a lo que mencionamos anteriormente: localización aislada, fuerte estigma del barrio, dificultades de acceso a servicios básicos, entre otras razones.

En muchos casos, los vecinos preferirían que sus viviendas estuvieran localizadas en otros barrios, ya sea en los territorios en los que residían anteriormente o en nuevos barrios de vivienda social con una mejor localización respecto a la ciudad. Es lo que surge en conversación con Rocío (28 años) y Daniela (23 años):

ENTREVISTADORA: ¿Te gusta vivir en este barrio?

Rocío: Y... sí [ríe]; sí, porque tenemos la casa acá, no nos quedó otra. Si tuviera la oportunidad de irme a otro lado, me voy.

ENTREVISTADORA: ¿A qué barrio te irías?

Rocío: Adonde yo vivía antes, a Acosta.

ENTREVISTADORA: ¿Qué te gusta de allá?

Rocío: Y... todo; que tenés todo cerca, no como acá... (Rocío, 28 años)

DANIELA: Y si me dicen te doy una casa, para allá me voy; es lo mejor para mis hijos...

En las expresiones de las vecinas se puede apreciar una fuerte valoración de la "casa propia" (Lindon, 2005, p. 4). Esto conduce a una forma de habitar reducida al microlugar; es decir, la casa es "su" lugar, pero ese sentido no se hace extensivo al entorno: el espacio barrial es concebido como negativo, un territorio con el que no pueden construir una identidad por pertenencia.

Lo anterior se relaciona con la modalidad de producción del territorio barrial y la relocalización de las familias en él. La política de vivienda implementada desarrolló la construcción de proyectos idénticos (tipologías, diseño de espacios verdes y de equipamiento, etcétera) de los barrios-ciudades, sin reconocer rasgos culturales e identitarios y necesidades habitacionales y de locación de los futuros pobladores. Por lo tanto, la participación de los vecinos en la producción de su territorio ha sido escasa, limitada a su acuerdo con ser trasladados, frente a la amenaza del desalojo de la villa y a las posibilidades de progreso que implica la "casa propia". Esto aparece en las expresiones de los vecinos en términos de "nos tiraron acá", "nos trajeron y ahora estamos olvidados", que dan cuenta de una compleja construcción de la subjetividad respecto de la experiencia de habitar el territorio en que se encuentran, que oscila entre la conformidad por la casa y la sensación de encierro, abandono, en un lugar aislado de la ciudad.

En Nueva Esperanza, el proceso de lucha, resistencia y reivindicación de los pobladores en la autoproducción del territorio, atravesado por fuertes disputas 
con otros actores, implicó una activa participación vecinal, constituyéndose en un momento de encuentro y de establecimiento de relaciones solidarias. En este proceso de construcción material del hábitat también se va produciendo territorialidad, sentidos de apropiación del lugar. Así, en los relatos de los entrevistados se aprecia el significado del esfuerzo invertido en este asentamiento. Como dice Rosa: "nosotros hicimos todo a pulmón, nosotros nunca tuvimos una ayuda; en realidad acá... acá fue duro para todos"; y también Irene: "no fue nada fácil, pero a la vez te sentís orgullosa de estar acá, porque vos la luchaste y al fin y al cabo es como que ganaste, porque estamos en nuestras casitas, un techo para tus hijos...”.

La representación del asentamiento producida por los pobladores es la de un barrio planificado y ordenado, una manera de establecer fronteras de diferenciación con los territorios de las villas, históricamente estigmatizados, y también da cuenta de las intenciones de una consolidación urbana: "los que han venido se han quedado asombrados, porque un asentamiento que esté como está acá no se ve en todos lados; porque es un asentamiento raro. Fíjate, si venís a la noche, está todo alumbrado, no tenés los cables colgando como si fuera una telarańa..." (Armando, 35 años). Al mismo tiempo, la organización comunitaria orientada a producir un barrio con servicios de calidad, con espacios verdes, con construcciones hechas con material; con acciones comunitarias, como copas de leche, espacios recreativos y deportivos, etcétera, configura parte de un imaginario de lo que es un barrio y de cómo se concibe el barrio que se va produciendo colectivamente.

\section{Reflexiones finales}

En este trabajo hemos presentado un análisis comparativo de dos territorios, cuyos orígenes han sido diferentes: un barrio de vivienda social producido por el Estado, y un asentamiento desarrollado a través de una toma de tierra organizada por un grupo de familias. Si bien -como desarrollamos a lo largo del trabajo- presentan rasgos disímiles no solo en la localización periférica y producción del hábitat, sino también en los sentidos construidos en torno a su territorio, podríamos decir que son resultantes de procesos segregativos.

A modo analítico, retomando a Carman, Neiva y Segura (2013), podríamos categorizarlos como espacios de segregación acallada y segregación agravada.

En la primera situación enmarcamos el caso de Ciudad de los Cuartetos, un territorio producto de la política de vivienda social dirigida a mejorar las condiciones de vida de la población de villas que se encontraban en riesgo ambiental, pero que estaban ubicadas en áreas centrales de la ciudad. Se trata de una política que tuvo como resultado el desplazamiento de las familias a la periferia, con menores oportunidades para el acceso a los recursos necesarios para la reproducción cotidiana y con una marcada diferenciación material y simbólica del barrio respecto del resto de la ciudad, a través de su arquitectura y denominación como barrios-ciudades. Así, los pobladores de Ciudad de los Cuartetos lo identifican como un lugar de encierro, abandonado, que se constituye en un territorio desvalorizado, con sentidos de habitabilidad reducidas a la vivienda. 
Como espacio de segregación agravada podemos interpretar el caso de Nueva Esperanza, donde los vecinos han sufrido prácticas represivas y de control por parte de las fuerzas de seguridad y de otros actores (empresas inmobiliarias) para lograr el desalojo y liberación de esa tierra de alto valor; los mismos que, en la actualidad, han cercado el asentamiento a través de tejidos perimetrales para contener su crecimiento. Sin embargo, a través de la organización colectiva, los vecinos pudieron resistir, autoproducir y apropiarse de su territorio, siendo un aspecto clave en los procesos de disputas de los sentidos y representaciones que ellos construyen de su territorio, y como disputa de los estigmas territoriales.

En ambos casos podemos identificar las fronteras materiales y simbólicas que se hacen presentes en el territorio como marcas que segregan y diferencian a su población a través del tejido urbano; entre ellas, el arco de entrada al barrio de vivienda social o el cerco perimetral en el asentamiento, marcas que, al mismo tiempo, contribuyen a la configuración de representaciones y estigmas sobre sus pobladores. Sin embargo, más allá de estos aspectos comunes, uno necesario de destacar se refiere a las claras diferencias en cuanto a la apropiación simbólica del territorio. Así, mientras que en el conjunto de vivienda social la valoración del territorio barrial es negativa, en el asentamiento planificado, producido y resistido de manera colectiva, los sentidos en torno a él dan cuenta de una identidad compartida y pertenencia al lugar que se van renovando con los proyectos y las visiones de futuro para el barrio.

En este sentido, el abordaje que presentamos y los resultados obtenidos nos ayudan a comprender la importancia de las estructuras simbólicas en la producción de los procesos de segregación. En primer lugar, en identificar que la producción de la estigmatización territorial, más allá de las características diferenciales de los territorios analizados, se vinculan a procesos de discriminación estructural, que no pueden ser pensados fuera de la lógica de las clases sociales. A partir de tal discriminación, los pobres y sus hábitats son identificados y etiquetados negativamente, más allá de si se trata de un barrio o una villa o asentamiento.

En segundo lugar, el estudio realizado nos permite reconocer la importancia de las percepciones territoriales como factores habilitantes o impedimentos para acceder a los servicios y recursos necesarios para la reproducción social cotidiana; $y$, a la vez, comprender que cuando tales percepciones se hacen estigmas, se constituyen en fuente de desventajas e instrumentos de diferenciación y de sostenimiento de las desigualdades sociales.

En tercer lugar, el trabajo nos ha llevado a valorar la participación de los pobladores en la producción y construcción del territorio como aspecto clave tanto de la apropiación del lugar, como de la generación de representaciones y prácticas en relación con sus barrios y las posibilidades de disputar los estigmas que recaen sobre ellos. Se trata de posicionamientos frente a la realidad territorial que pueden dar curso a sentidos diferentes de la experiencia de vivir en territorios segregados, y también recrear acciones en búsqueda de estrategias que tensionen las políticas públicas estatales y los procesos de desigualdad social. 


\section{Referencias bibliográficas}

Abramo, P. (2007). A cidade com-fusa a mão inoxidável do mercado e a produção da estrutura urbana nas grandes metrópoles latino-americanas. Revista Brasileira de Estudos Urbanos e Regionais, 9(2), 25-54. http://dx.doi.org/10.22296/2317-1529.2007v9n2p25

Bourdieu, P. (1999). La miseria del mundo. Buenos Aires: Fondo de la Cultura Económica.

Caldeira, T. (2010). Espacio, segregación y arte urbano en el Brasil. Buenos Aires: Katz.

Carman, M., Neiva V. \& Segura, R. (2013.) Introducción. Antropología, diferencia y segregación urbana. En M. Carman, V. Neiva \& R. Segura (coords.) Segregación y diferencia en la ciudad (pp. 11-34). Quito: Facultad Latinoamericana de Ciencias Sociales, Flacso-Ecuador; Consejo Latinoamericano de Ciencias Sociales (Clacso); Ministerio de Desarrollo Urbano y Vivienda, Ecuador.

Cravino, M. C. (2013). Transformaciones urbanas y representaciones sociales de la ciudad en el Área Metroplitana de Buenos Aires de las últimas décadas. En Seminario Internacional A Cidade Neoliberal na América Latina: Desafios teóricos e políticos. Río de Janeiro, 6, 7 y 8 de noviembre de 2013. Instituto de Pesquisa e Planejamento Urbano e Regional, Universidade Federal do Rio de Janeiro (IPPUR/UfRJ).

De Alba, M. (2010). Representaciones sociales y el estudio del territorio: aportaciones desde el campo de la Psicología Social. En S. González (coord.), La integración de la dimensión espacial en las ciencias sociales y humanidades: Un proyecto docente interdisciplinario. Cuajimalpa, México: Universidad Autónoma Metropolitana, Laboratorio de Análisis Socioterritorial.

Di Virgilio, M. M. \& Perelman, M. (2014). Ciudades Latinoamericanas. La producción social de las desigualdades urbanas. En M. Di Virgilio \& M. Perelman (coords.), Ciudades latinoamericanas: desigualdad, segregación y tolerancia (pp. 8-19). Buenos Aires: Consejo Latinoamericano de Ciencias Sociales (Clacso).

Duhau, E. \& Giglia, A. (2008). Las reglas del desorden: habitar la metrópoli. Ciudad de México, México, D.F.: Siglo xxi Editores, Universidad Autónoma Metropolitana.

Elorza, A. L. (2016). Segregación residencial socioeconómica y la política pública de vivienda social. El caso de la ciudad de Córdoba (Argentina). Revista Cuaderno Urbano, 20(20), 71-94. https://bit.ly/2QhFduc

Elorza, A. L. (2009). Estrategias de reproducción social de familias relocalizadas, entre la adaptación y el cambio. Conciencia Social, 9(12), 53-59.

Goffman, E. (1998). Estigma: la identidad deteriorada. Buenos Aires: Amorrortu Editores.

Kessler, G. (2012). Las consecuencias de la estigmatización territorial. Reflexiones a partir de un caso particular. Espacios en blanco. Serie indagaciones, 22(1), 165-197. https://bit. ly/2A8NOoM

Lindon, A. (2005). El mito de la casa propia y las formas de habitar. Scripta Nova, 9, 194 (20). http://dx.doi.org/10.1344/sn2005.9.937

Marengo, C. \& Elorza A. (2009). Globalización y políticas urbanas. La política habitacional focalizada como estrategia para atenuar condiciones de pobreza urbana: los programas implementados en Córdoba y los desafíos pendientes, Revista Cuaderno Urbano, 8(8), 7-33. https://bit.ly/2qX7rvV 
Marengo, C. \& Elorza A. (2016). Vivienda social en Córdoba, efectos en la segregación residencial y el crecimiento urbano (1991-2008). Revista INVI, 31(86), 119-144. http://dx.doi.org/10.4067/S0718-83582016000100005

Mayorga, J., García, D. \& Hernández, L. (2017). Calidad de vida y su correlación con los precios del suelo: aproximación a la segregación residencial en Bogotá. Cuadernos de Vivienda y Urbanismo, 10(19), 22-40. http://dx.doi.org//10.11144/Javeriana.cvu1019.cvcp

Merklen, D. (1997). Un pobre es un pobre. La sociabilidad en el barrio; entre las condiciones y las prácticas. Revista Sociedad, (11), 21-64. https://www.margen.org/social/merklen.html

Programa de Naciones Unidas para el Desarrollo (PNUD) (2009). Segregación residencial en Argentina. https://bit.ly/2TvvEX0

Mele, P. (2016). ¿¿Que producen los conflictos urbanos?. En F. Carrión \& J. Erazo (coords.), El derecho a la ciudad en América Latina, Visiones desde la politica (pp.127-158). México, D.F.: Coordinación de Humanidades, Programa Universitario de Estudios sobre la Ciudad, Centro de Investigaciones sobre América Latina y el Caribe, International Development Research Centre IDRC/CRDI, Consejo Latinoamericano de Ciencias Sociales. https://bit.ly/2Q8NIYk

Rodríguez Chumilla, I. (2006). Vivienda social latinoamericana: la clonación del paisaje de la exclusión. ACE: Architecture, City and Environment = Arquitectura, Ciudad y Entorno, 1(2), 20-55. http://dx.doi.org/10.5821/ace.v1i2.2342

Ruiz Tagle, J., Labbé, G., Álvarez, M., Montes, M. \& Aninat, M. (2016). Una teoría del espacio institucional de barrios marginales. Herramientas conceptuales desde una investigación en curso en Santiago de Chile. En Conferencia Internacional Contested Cities: Del conflicto urbano a la construcción de alternativas, Madrid, 2016. https://bit. ly/2PKsUa4

Sabatini, F. (2006). La segregación social del espacio en las ciudades de América Latina. Washington, D.C.: Banco Interamericano de Desarrollo (віD). https://bit.ly/2wK4HE5

Sabatini, F., Wormald, G. \& Rasse, A. (2013). Segregación de la vivienda social: ocho conjuntos en Santiago, Concepción y Talca. Santiago: Colección Estudios Urbanos Uc.

Santillán Cornejo, A. (2015). El imaginario social como campo de disputas por la significación de la segregación urbana. En II Seminario Internacional sobre Teoría Urbana 18-20 de febrero de 2015, Universidad Nacional de Colombia (sede Medellín).

Saraví, G. (2008). Mundos aislados: segregación urbana y desigualdad en la Ciudad de México. EURE, 34(103), 93-110. http://dx.doi.org/10.4067/S0250-71612008000300005

Segura, R. (2006). Segregación residencial, fronteras urbanas y movilidad territorial. Un acercamiento etnográfico. Buenos Aires: Instituto de Desarrollo Económico y Social Cuadernos (IDES), Cuadernos del IDEs. https://bit.ly/2PLq7xu

Segura, R. (2012). Elementos para una crítica de la noción de segregación residencial socioeconómica: desigualdades, desplazamientos e interacciones en la periferia de La Plata. Revista Quid, 16(2), 106-132. https://bit.ly/2TunSNn

Varela, O. \& Cravino, M. C. (2008) Mil nombres para mil barrios. Los asentamientos y villas como categorías de análisis y de intervención. En M. C. Cravino (coord.), Los mil barrios (in)formales: aportes para la construcción de un observatorio del hábitat popular del área metropolitana de Buenos Aires. Los Polvorines, Argentina: Universidad Nacional de General Sarmiento. 
Wacquant, L. (2007). Los condenados de la ciudad. Gueto, periferias y Estado. Buenos Aires: Siglo Xxi Editores.

Wacquant, L., Slater, T. \& Borges Pereira, V. (2014) Estigmatización territorial en acción. Revista INVI, 29 (82), 219-240. http://dx.doi.org/10.4067/S0718-83582014000300008

Zilocchi, G. (2007). Villas miseria. La vivienda de los más pobres en la etapa industrial moderna 1930- 1970. Buenos Aires: El Cid Editor. 